\title{
Patient opinions on medicine-use review: exploring an expanding role of community pharmacists
}

\author{
This article was published in the following Dove Press journal: \\ Patient Preference and Adherence \\ 10 April 2017 \\ Number of times this article has been viewed
}

\author{
Sirinya Aimaurai' \\ Atthapinya Jumpated' \\ Ines Krass ${ }^{2}$ \\ Teerapon Dhippayom' \\ 'Faculty of Pharmaceutical Sciences, \\ Naresuan University, Phitsanulok, \\ Thailand; ' ${ }^{2}$ aculty of Pharmacy, \\ University of Sydney, Sydney, \\ NSW, Australia
}

Correspondence: Teerapon Dhippayom Faculty of Pharmaceutical Sciences, Naresuan University, 99 Moo 9 Tambon Tha Pho, Phitsanulok 65000, Thailand Tel +6655961839

Fax +66 55963731

Email teerapond@nu.ac.th
Background: Current evidence supports the benefit of medicine-use review (MUR) for the safe and effective use of medicines. However, little is known about opinions of consumers regarding their preference for undertaking MUR, especially in the developing world, eg, in some Asian countries. We aimed to explore patients' opinions about potential MUR and other enhanced services provided by community pharmacists.

Patients and methods: A qualitative study using focus groups was conducted at Naresuan University's community pharmacy, Phitsanulok, Thailand. MUR-naïve patients were recruited from two pharmacies in Phitsanulok. All focus groups were audio-recorded, transcribed, and thematically analyzed.

Results: Twenty participants attended four focus groups. The following themes were identified: 1) requirement and need for the service, 2) accessibility and convenience of receiving the service, 3) pharmacist attributes needed in delivering the service, and 4) how to promote the use of MUR successfully. The majority of participants had poor understanding about their medicines and were interested in receiving a MUR service. Regarding accessibility, convenience and close proximity of pharmacies to homes were deemed to be supportive of participants to use the service. However, several potential barriers to uptake were identified: perceived difficulty on the part of recipients in making time to receive the service and the inconvenience of having to provide medicines/records of medicines to pharmacists. The following domains of pharmacists' characteristics were viewed as supportive determinants: personality (friendliness and confidence in giving information) and attitude (willingness to provide the service and not commercially oriented). The participants suggested that promoting the services using a mix of strategies would increase an awareness of MUR service.

Conclusion: Recognizing the unmet needs of patients for information on their medicines provides a good opportunity for community pharmacists to offer an MUR service to ensure quality use of medicines in the community.

Keywords: medicine-use review, pharmacy service, community pharmacy, community pharmacist, preference

\section{Background}

If medicines are required for the treatment of medical conditions, they must be taken appropriately to achieve maximum efficacy and minimum risk of harm to the patient. However, failures in accomplishing treatment outcomes and/or the continuing occurrence of preventable adverse drug events represent important public health issues worldwide. One of the major causes of this is poor or inconsistent medication adherence. ${ }^{1,2}$ Other factors, such as health care providers' communication and behavior $^{3}$ and features of health service organizations, ${ }^{4}$ also contribute to problems in the safe and effective use of medicines. Of the intervention strategies that have 
been tested to tackle this issue, those with the strongest evidence for bringing about improvement in the quality of use of medicines include medicine self-monitoring and self-management programs, simplified dosing regimens, and direct involvement of pharmacists in medicine management (eg, medication reviews). ${ }^{5}$

The aim of medication reviews is to improve the quality, safety, and appropriate use of medicines. ${ }^{6}$ Medication reviews can be classified into four types: 1) prescription review, 2) adherence-support review, 3) clinical review, and 4) clinical review with prescribing. ${ }^{7}$ Prescription reviews are usually part of the pharmacist's routine in dispensing medication, whereas adherence-support reviews are an enhanced service aimed at helping patients use their medicines more effectively. ${ }^{6}$ Adherence-support review, also known as medicine-use review (MUR), is available in several countries, such as the US, Canada, Australia, New Zealand, and several countries in Europe, including the UK, Switzerland, the Netherlands, Portugal, and Scandinavian countries. ${ }^{7,8}$ Although details of the service vary between countries, the possible interventions provided in the context of these reviews address similar issues relating to a patients' medication-taking behavior, such as provision of advice on correct and safe medication use, eg, identification of adverse effects, checking patients' medication-administration technique in the use of specific medication-dosage forms, eg, inhalers, and identification of the need for a change in medication, medication dose, and/or dosage form. ${ }^{7}$

In 2014, the Thai National Health Security Office (NHSO), an authority that is responsible for the universal health coverage in Thailand, signed an agreement with the Community Pharmacy Association Thailand to provide financial support for remuneration to be paid to community pharmacists nationwide for provision of a number of enhanced services, such as screening for metabolic diseases, health education, and smoking cessation. However, different regions may have adopted different types of service, taking account of local needs, as well as the expertise and interest of participating community pharmacists.

MUR was one of the enhanced services offered by 20 pharmacies in the NHSO region of Phitsanulok in the middle of Thailand. To be able to provide an MUR service, participating pharmacists had to attend a 1-day workshop to gain understanding about the scope and guidelines for MUR and other enhanced services, including screening for metabolic diseases and the smoking-cessation service. After completing the workshop, pharmacists were given a unique code number to use when they filled in their enhanced-service records online for reimbursement. Various advertising materials to promote the awareness of enhanced pharmacy services to the public were also distributed. These included advertising posters to be placed in front of participating pharmacies and promotion leaflets distributed to the local population in close proximity to the pharmacies. Patients eligible for MUR services were those who met one of the following criteria: taking five or more medicines for chronic non-communicable diseases, taking nonsteroidal anti-inflammatory drugs, anticoagulants, antiplatelets, or diuretics, and having known drugrelated problems. Pharmacists identified eligible patients by asking pharmacy customers about their current medication when performing a routine service. Those who asked for the service after seeing the advertising signs were also reviewed by pharmacists if they were eligible to receive the MUR service. Patients who met the service criteria were informed about the scope and benefit of the service. If interested in receiving the service, they were asked to bring back all their medicines for review on their next convenient visit. Pharmacists provided the MUR service to patients by assessing their medication adherence and their understanding about their medicines, including the indication and dosage administration. Pharmacists also checked for duplicate medication, physical appearance, and expiry dates of the medicines, as well as signs and symptoms of adverse drug reactions.

However, the number of patients who received this service was relatively low, ie, 61 patients during March 1 to September 30, 2015. In order to promote the use of MUR service effectively to achieve the safe and effective use of medicines in the community, a better understanding of consumers' information needs and expectations is required.

At present, little is known about consumer demand for and preferences related to the provision of an MUR service by community pharmacists. Although several studies have been conducted to gain a better understanding of public views and expectations of enhanced pharmacy services, ${ }^{9-11}$ most studies did not specifically address MUR. Moreover, consumer opinions and preferences in one country may not necessarily apply in other populations, as their perspectives may depend on their experience of pharmacy services under different health care systems. To the best of our knowledge, no studies have explored this topic in the developing world/Asian countries. We thus conducted this study to address these gaps with the following specific objectives: to identify potential unmet needs in the use of medicines and to explore patient preferences for MUR and other enhanced pharmacy services. 


\section{Patients and methods Setting and study design}

This study was conducted in Phitsanulok, Thailand, which is in an area where the MUR service is offered. A focus-group approach was used to address the study objectives.

\section{Participants}

Participants were patients who did not have experience of using the MUR service and met one of the following criteria: 1) used one or more medicines for chronic non-communicable diseases and 2) experienced one or more drug-related problems during the recruitment period. A convenience-sampling technique was used to recruit participants into the focus groups. This was undertaken by pharmacists on duty in the two pharmacies that offered an MUR service, ie, Naresuan University Community Pharmacy and another independent pharmacy. Participants were compensated for their time with B200 (US\$5.6) cash at the end of the focus-group discussion.

\section{Focus-group topic guide}

A topic guide was developed, following a review of relevant literature, ${ }^{10,12,13}$ to provoke opinions and generate discussion. The focus-group topic guide and questions were tested on five volunteers to assess content validity and enhance facilitation skills. The final topic guide and questions consisted of seven issues (Supplementary material): 1) experiences and opinions on the use of pharmacy services, 2) drug-related problems, 3) understanding of the use of medicines, 4) need and perceived benefit of the MUR service, 5) barriers to and facilitators of using MUR, 6) how to promote uptake of the MUR service, and 7) contribution of community pharmacies in improving safe and appropriate use of medicines.

\section{Conduct of the focus group}

The focus groups took place in a meeting room at Naresuan University Community Pharmacy between March 6 and March 19, 2016, and lasted approximately 50-70 minutes each. Potential participants identified from the two pharmacies were given an information sheet for research participants that contained information about the MUR service. Before commencing each focus group, the facilitators also verbally explained the scope, process, and expected benefits of the MUR to participants. In brief, the explanation covered the following information:

- patients who are interested in using the MUR service need to bring back all their medicines for review on their next convenient visit;
- pharmacists provide the MUR service to patients by assessing their medication adherence and their understanding about their medicines, including indication and dosage administration;

- pharmacists also check for duplicate medication, physical appearance, and expiry dates of medicines, as well as signs and symptoms of adverse drug reactions;

- patients should expect to gain an understanding about their own medication, such as why they need to take it and how to take it, what the main adverse effects are, and how to observe these, as well as what to avoid when taking their medicines; any concerns that may compromise their adherence to medication would be discussed and addressed;

- time for undertaking the MUR service varies and depends on the number of medicines used and problems identified.

The same facilitators (SA and AJ) facilitated the group discussion according to the focus-group topic guide and were observed by TD. All focus groups were audio-recorded and transcribed ad verbatim.

\section{Analysis}

In parallel with focus groups, transcripts were analyzed independently by researchers (SA, AJ, and TD) using a method of constant comparison and coded using both open and selective coding. ${ }^{14}$ Researchers met regularly to discuss and agree on the emergent themes. Focus groups were continued until saturation of themes was reached..$^{15}$ The quotations were grouped into themes prior to identifying subthemes. Any discrepancies between the researchers' views were settled through discussion and consensus based on reference to the original data.

\section{Ethical considerations}

Information sheets were provided to potential participants during the recruitment stage, and written informed consent was obtained from each participant prior to participation for this study. This study was approved by the Naresuan University research ethics committee (approval 826/58).

\section{Results}

Saturation of themes was achieved after four focus groups with a total of 20 participants. There were more female than male participants (13 vs 7), with ages ranging from 36 to 70 years (Table 1). Almost all participants had longterm medical conditions, including hypertension, diabetes, and hypercholesterolemia. In addition to prescribed 
Table I Details of focus-group participants

\begin{tabular}{|c|c|c|c|c|c|}
\hline Group & Respondent & Sex & $\begin{array}{l}\text { Age } \\
\text { (years) }\end{array}$ & Medical conditions & $\begin{array}{l}\text { Use of herbal medicines } \\
\text { or dietary supplements }\end{array}$ \\
\hline \multirow[t]{7}{*}{$\mathrm{I}$} & 1 & Female & 55 & Hypercholesterolemia & Yes \\
\hline & 2 & Male & 47 & Hypertension and diabetes & Yes \\
\hline & 3 & Female & 36 & No* & Yes \\
\hline & 4 & Female & 63 & Hypertension, hypercholesterolemia, and cerebrovascular disease & Yes \\
\hline & 5 & Male & 57 & Diabetes and hypertension & No \\
\hline & 6 & Male & 50 & Diabetes and hypertension & No \\
\hline & 7 & Male & 69 & Hypertension & No \\
\hline \multirow[t]{4}{*}{2} & 8 & Female & 38 & Hypertension and hypercholesterolemia & Yes \\
\hline & 9 & Female & 50 & Hypertension & No \\
\hline & 10 & Female & 58 & Allergic rhinitis & Yes \\
\hline & 11 & Male & 66 & Hypertension & No \\
\hline \multirow[t]{5}{*}{3} & 12 & Female & 57 & Hypertension & No \\
\hline & 13 & Female & 57 & Hypertension & No \\
\hline & 14 & Male & 42 & Diabetes & No \\
\hline & 15 & Female & 68 & Hypertension and diabetes & Yes \\
\hline & 16 & Female & 70 & Hypertension & Yes \\
\hline \multirow[t]{4}{*}{4} & 17 & Female & 61 & Diabetes, hypertension, and hypercholesterolemia & Yes \\
\hline & 18 & Male & 40 & Chronic low-back pain & Yes \\
\hline & 19 & Female & 63 & Hypertension, hypercholesterolemia, and knee osteoarthritis & No \\
\hline & 20 & Female & 70 & Hypertension and allergic rhinitis & No \\
\hline
\end{tabular}

Note: *Met inclusion criteria for having drug-related problems.

medicines for their chronic diseases, half of the participants reported use of herbal medicines and/or dietary supplements. The key themes identified in association with patient preferences for the MUR service were 1) requirement and need for the service, 2) accessibility and convenience to receive the service, 3) pharmacist attributes needed in delivering the service, and 4) how to successfully promote the use of MUR (Figure 1).

\section{Requirement and need for the service}

Problems with regard to the understanding of their medicines were brought up by most participants. These included uncertainty about how to use and what effects should be expected from the medicines, inability to identify expiry dates, and concerns about concomitant use with other medicines:

I used to have loads of medicines at home, and then I forgot what they were used for and whether I can still use them. [R10]

I use medicines that I get from the hospital, and wonder if it is harmful if I take other herbal medicines. [R17]

Sometimes I wonder what this particular medicine is indicated for. Sometimes I just discard some medicines if

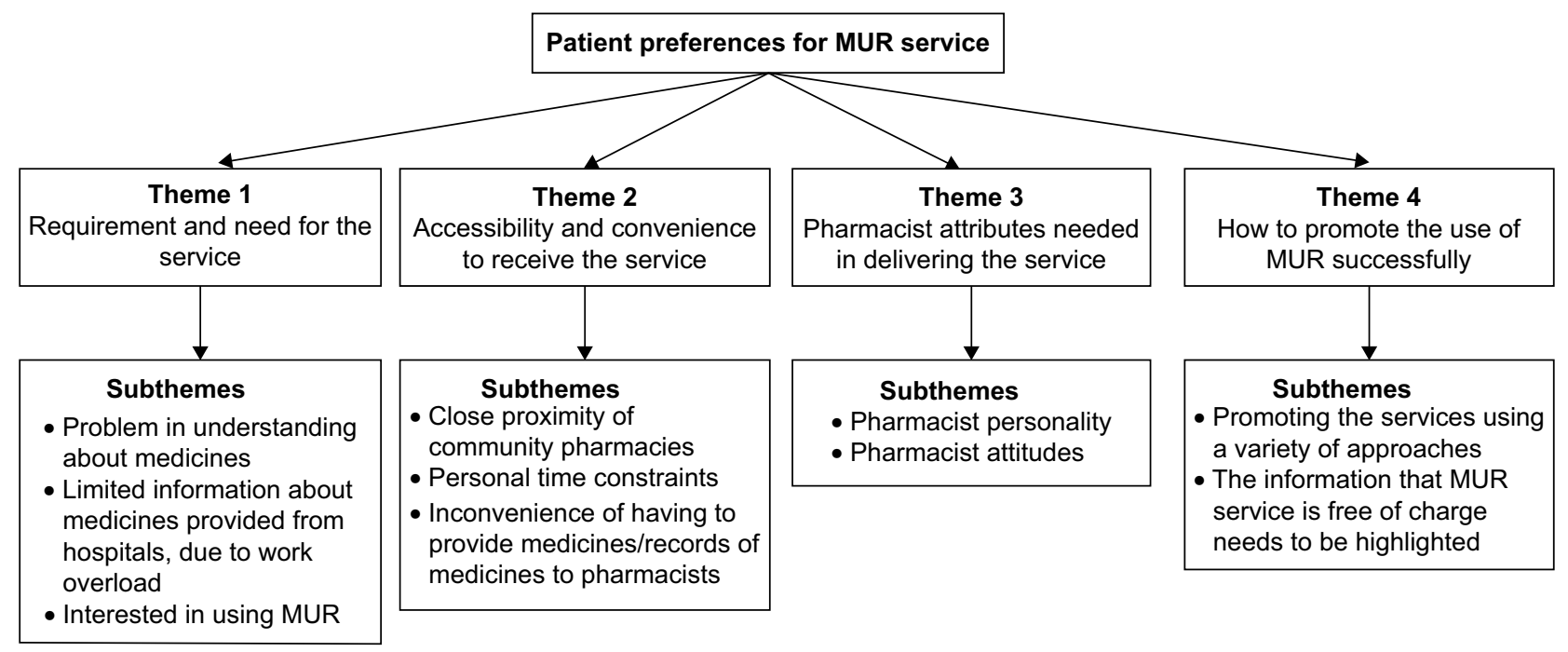

Figure I Themes and subthemes that emerged from the focus groups. Abbreviation: MUR, medicine-use review. 
I don't know what benefit I should expect from them. I don't

even know when the medicines are expired. [R18]

Work overload among hospital pharmacists and other health care professionals that precluded patients from obtaining more information about their dispensed medicines was also noted:

We should know that the hospital is very crowded with lots of patients, so they (pharmacist) can only give us brief information about how to take medicines. [R13]

It is convenient to come to a pharmacy so that pharmacists can help checking our medicines. Even though we have to spend a whole day in the hospital for our visit, the doctors and nurses do not have time to advise us on medicines, as it was jam-packed there and the waiting time is so long. [R16]

Occasionally when I went to hospital, pharmacists had to serve a lot of patients who had been waiting. This made them not able to respond completely to my questions. [R18]

Having been informed about the scope of MUR, the majority of participants expressed interest in using the service:

I would like to use this service. Sometimes when I visit the hospital for follow-up, I did not see the same doctor who changed my treatment regimen, which made me feel uncomfortable to discuss the effects of new medicines with other doctors. I think this service would allow me to discuss with the pharmacist out of office hours, which is very good. [R5]

It would be good if this service is available so that I can bring my medicines for the pharmacist to check and advise about effects of the medicines and whether I should continue using these medicines. [R13]

I am interested in this service, and I would bring all my medicines for the pharmacist to check if I can use herbal medicines with my prescribed drug. [R17]

\section{Accessibility and convenience of receiving the service}

Close proximity of community pharmacies was seen as an advantage and supportive of participants using the service:

It saves time and is convenient, because we don't need to wait for hours to get service [compared to the hospital]. [R8]

I come to the pharmacy quite often, because it is near. When I have something I want to know, I would come here, since it is close to my house, which is very convenient. [R9]
However, participants perceived that their personal time constraints might make it difficult to make use of an MUR service:

I wish to come, but I normally don't have much free time. [R1]

I'd like to come, but I also have something else to do, which I think is a barrier for me to use the service. [R3]

The barrier is time, because I have work to do. I have no problem with transport. [R14]

To perform the MUR service comprehensively, pharmacists need to ask patients to bring all their medicines or a list of medicine at the next visit, as most pharmacies do not have a record of patients' medicines. For some participants, the inconvenience of having to provide medicines/records of medicines to pharmacists was seen as a potential obstacle to using the MUR service, while many others indicated that they would have no problem bringing their medicines for the next visit:

I will definitely come back with my medicines. [R5]

It is inconvenient, because I take a lot of medicines. I cannot remember the name ... sometimes we take medicines without reading the label, right? This is my routine. So I think it's not convenient for me to bring back my medicines. [R2]

\section{Pharmacist attributes needed in delivering the service}

The following domains of pharmacists' attributes were viewed as supportive determinants: 1) personality (friendliness, modestly dressed, and good communication skills) and 2) attitude (willingness to provide the service and not commercially oriented). Following are statement with regard to pharmacist personality:

It is a first impression. If they (pharmacist) smile, it means they are happy to serve us. [R2]

I think friendliness is important. For we are Thai, friendliness make us feel like we are family. And if we have problems, we would consult our family, who we can trust. It will make us feel confident to talk about our problem. For sick people, they are quite vulnerable and anxious, so they won't talk to those who they don't trust. [R5]

Pharmacist's character is important. It would make us feel that the pharmacist is knowledgeable and capable to provide a service if they can clearly respond to the queries and speak fluently. [R8]

I wish to see a bright smiling face, not a frowning one, when we open the door and get in. A nice word would encourage us to use the service. [R12] 
The following are statements regarding pharmacist attitudes:

The pharmacist should pay attention when communicating with patients, and should not force selling their products. [R9]

Some pharmacies would only focus on selling drugs and only ask which drugs we want. Customers do not normally ask them questions. I wish they (pharmacists) would ask us more about our problems. [R15]

\section{How to promote the use of MUR successfully}

The participants suggested that promoting the service using a variety of approaches would increase awareness of the MUR service. These included a mass-media promotional campaign, being directly informed by pharmacists, and by word of mouth from patients who received the service:

There should be a sign, any kind of sign, at the point of service that this service is offered here. [R5]

Advertising the service is important. For example, listening to radio advertisements every day is like hypnotizing. [R10]

A good service will impress people. We Thai people always like to spread the news. [R2]

There will be a word-of-mouth phenomenon if the service is good, the pharmacists are nice, and able to explain things clearly. [R12]

They recommended that the details and process of the service and that it is free of charge need to be highlighted.

At first, I'm not quite sure what this service will cover. I think many patients would not understand it either. Normally, we come to the pharmacy just to buy medicines that run out ... I think the staff should keep informing us on details of the service. Anyhow, I think it's good to have this kind of service. [R2]

Knowing that it is free of charge will encourage people to use this service. [R19]

In addition, participants suggested that additional services, such as keeping records for patients who receive the MUR service, providing health checks for self-monitoring, and having a private consultation area, would support the use of this service:

The pharmacies should keep customer records or a patient history. [R2]
I wish to have a blood glucose-monitoring service, so that we can have an idea if there's anything wrong with our body. [R14]

I wish to see blood testing and a blood pressuremonitoring service. [R16]

There should be a partition to separate the service area for privacy. [R8]

Talking over the counter sometimes is not convenient when there are other customers. It would be more appropriate to have a dedicated consultation area. [R14]

\section{Discussion}

The results of this study highlighted a significant unmet need for medicine information and education among the study participants, with demonstrably poor levels of health literacy on medicines and limited opportunity to access medicine information at the time of dispensing in the hospital. It is thus unsurprising that there was universal expressed interest in using an MUR service, notwithstanding some personal time constraints and the inconvenience of having to bring medicines/records of medicines to the community pharmacy. Pharmacists with a friendly disposition, positive attitudes, and good communication skills were perceived to be more likely to create demand for the service. Although an MUR service had been available for over a year in 20 community pharmacies, awareness of the service among eligible patients was low. A variety of approaches are needed to promote and encourage uptake of the service.

The strength of the qualitative approach used in this study is that it allowed an in-depth exploration in an underresearched area to inform future work. Focus groups were chosen to overcome the limitation of interviews, where participants may be reluctant to discuss their concerns. The group environment is particularly useful for exploring not only what people think but how they think and why they think that way. ${ }^{16}$ Due to the nature of the focus-group process, input from individual participants to present their views and opinions is required. Therefore, dominant participants may have undue influence over the topics and detail discussed. In the present study, none dominated the discussion, although a few quiet participants were observed. However, the facilitators tried to encourage contributions from those quiet participants by specifically directing questions and inviting them to share their views on the issues discussed. Although the themes derived from a small number of participants may limit generalization, this has provided a clearer understanding of the needs, attitudes, and preferences of patients with respect to the understanding of their medications, and provides 
initial evidence to support appropriate policy development to enhance the use of the MUR service.

\section{Requirement and need for the service}

Although community pharmacy provides dispensing services for prescription medicines, only a small fraction of prescriptions are actually filled at a community pharmacy.${ }^{17}$ This is because drug-prescribing and -dispensing services are not formally separated in Thailand. As a result, physicians in private clinics can both prescribe and dispense medicines. Every hospital also has a pharmacy department to dispense medicines with their outpatients. Based on the high volume of outpatient visits to hospitals, the limited number of hospital pharmacists may not be able to inform patients comprehensively when dispensing their medicines. It is thus not surprising that the focus-group participants had limited knowledge about their medications. This finding concurs with other studies that showed that a substantial proportion of Thai patients have inadequate health literacy, including knowledge about medication used in various chronic diseases, such as hypertension ${ }^{18}$ and schizophrenia. ${ }^{19}$ This problem needs to be addressed, as health literacy is positively associated with medication adherence. ${ }^{20,21}$

The perceived low level of understanding about medication may explain the expressed interest in MUR among focus-group participants. These information needs among patients create an opportunity for community pharmacists to offer enhanced services like MUR, as found in this study, and other services, such as provision of information to patients with type 2 diabetes, ${ }^{22}$ especially those who are newly diagnosed. ${ }^{23}$

\section{Accessibility and convenience of receiving the service}

The convenience of access to community-pharmacy services has always been the strength of this health care setting. ${ }^{24,25}$ Despite the convenience of the community-pharmacy setting, time pressures for consumers visiting the pharmacy may still represent an obstacle to utilizing the MUR service, as has been previously reported. ${ }^{26}$ This problem is particular to the schedules of individual consumers, and also depends on the times the MUR is offered in the pharmacy, and is thus difficult to address at a system level. Appropriate strategies to overcome the barrier of perceived time constraints require further investigation.

\section{Potential of pharmacists to deliver the service}

While reservations about the pharmacists' skill and knowledge have been reported in services that involved disease management, ${ }^{23}$ health advice, ${ }^{11}$ or unfamiliar services, ${ }^{10}$ doubt about pharmacist knowledge was not a main concern among focus-group participants in this study. This was probably due to the fact that MUR is a service that focuses on medicines, on which the general public perceive pharmacists to be experts. Findings from other studies echo the perception that an ideal role for pharmacists is linked to perceptions of expertise on medicines. ${ }^{9,27}$

Fear or embarrassment to ask questions was noted by some focus-group participants. This aligns with findings from other studies, ${ }^{26,28}$ despite differences in culture and health care systems, which indicates a universal problem of professional communication. To address this problem, it was suggested that pharmacists could help to create an approachable and relaxed environment to encourage the consumer to inquire and engage in the service. This accords with findings by Latif et al, ${ }^{29}$ where patients' relationships with the pharmacy staff appeared to be an important determinant of patients' acceptance of an invitation to undertake an MUR service.

Concern regarding perceived conflict of interest, where pharmacists might seek to profit from MUR services, was also a concern raised in this study and by others. ${ }^{30}$ This indicates that the public views the community pharmacist as a business-oriented health care provider, with the result that the MUR service may be seen as untrustworthy. ${ }^{26}$ Highlighting that this MUR service is free of charge might help alleviate this concern.

\section{Pharmacist attributes needed in delivering the service}

Similar to findings from other studies, ${ }^{11,31}$ the lack of awareness of the service found in this study could explain why the use of the MUR service was limited. This phenomenon occurred despite the implementation of several promotion campaigns to raise the awareness of enhanced communitypharmacy service in the NHSO Phitsanulok area. These included posters/banners at participating pharmacies, complimentary paper bags that contained information about the MUR service, and flyers distributed to the general public. ${ }^{32}$ The focus-group discussion enabled further exploration of some potential promotional approaches that should be advocated to gain attention effectively from pharmacy customers to use the service.

In addition, one of the possible reasons that the MUR service was not recognized by patients may be associated with inertia within the participating pharmacies. Findings from another study ${ }^{33}$ suggested that the organizational setting, ie, multiple or independent pharmacies, is an important 
factor influencing the uptake of MUR. As all 20 participating pharmacies that offered the MUR service in Phitsanulok were independent pharmacies, there was no organizational pressure, as seen in UK pharmacies, to influence the uptake of this service among these pharmacists. Other factors influencing the uptake of the MUR service by pharmacists need further exploration and to be addressed accordingly.

Lack of a private consultation area is still an issue of concern for enhanced community-pharmacy services, expressed in this study and others. ${ }^{9,23}$ It was also found that pharmacists with access to a consultation area performed significantly more MURs than those who did not. ${ }^{34}$

\section{Policy implications}

Despite proven benefits on good-quality use of medicines, ${ }^{5}$ the uptake of the MUR service was lower than expected, especially during the initial phase in this setting and others. ${ }^{34,35}$ According to findings in this study, policy advocacy to promote the use of the MUR service should take into account the following factors: pharmacists, patients, and supporting factors.

While findings from other studies suggested that the limited use of enhanced pharmacy services is likely due to a lack of public trust, ${ }^{10}$ this did not appear to be the case in this study. Participants emphasized that the friendliness of pharmacists was an important factor encouraging them to ask for the MUR service. A training program for pharmacists to provide the MUR service should not focus only on adherence-support skills but also on how to create an approachable environment to encourage consumers to engage the service.

Lack of awareness appeared to be the main reason for the low uptake of the MUR service by eligible patients in this setting. As has been suggested previously, ${ }^{9,11}$ an appropriate promotional campaign, especially those suggested by the focus-group participants in this study, should be considered to publicize this service to potential users. The national campaign in English - "Ask your pharmacist" - was shown to be successful in informing and gaining acceptance from the public for using enhanced pharmacy services. ${ }^{12}$ Policy makers may need to consider promotional strategies and allocating a marketing budget, in addition to a budget for service reimbursement, in response to the poor awareness of the MUR service identified in this study.

Within the current health service system, community pharmacies in Thailand do not generally dispense prescribed medicines, and hence keeping records of patients' medicines is not routine practice for community pharmacists. ${ }^{17}$ Since the MUR requires a comprehensive review of all patients' medicines, patients are asked to come back with their medicines or list of medicines to commence the service, which may be inconvenient and discourage participation. This could be addressed by having a medication-record system in pharmacies or allowing pharmacists access to the patients' NHSO record. Another approach is to provide an incentive to encourage patients to come back with their list of medicines. Further research is needed to determine the most effective incentive in this population.

\section{Limitations}

Several potential limitations are acknowledged, specifically the sample-selection bias. A possible source of bias could be that consumers who opted to participate in the focus groups may have been those with strong views on pharmacy services. However, participants in this study were diverse in terms of factors that might have an impact on their needs and opinions, such as number of medical conditions and the use of other products, ie, herbal medicines and dietary supplements. Although sex heterogeneity may have affected the issues discussed, as well as contributions of the minority sex, this may not have had much impact on the results of the present study, since the discussion was not related to sex-sensitive topics. In addition, the focus group was continued until theme saturation was achieved to ensure that it covered the range of diverse opinions from the eligible population. Another limitation was that it could not include the views of those who have experienced using the MUR service, due to the limited number of MUR users. However, it was suggested that considering the views of service nonusers is important to reach eligible populations who may not specifically be seeking a health intervention. ${ }^{10} \mathrm{We}$ thus believe that investigating the views of MUR-naïve patients appropriately met the research aims to explore what factors would influence those eligible for MUR to engage with this service.

\section{Conclusion}

Given the unmet needs of those seeking information on medicine use, there are clear opportunities for pharmacists to become more proactive in providing the MUR service to promote the safe and effective use of medicines. Understanding patients' lack of understanding of medicines, as well as views of patients on MUR services, identified in this study will help inform the development of services to suit patients' needs and to engage them to make use of such services. The challenge is for pharmacists to address these perceived barriers by creating a friendly and relaxed environment and becoming proactive in promoting their capacity to deliver the MUR service. 


\section{Acknowledgments}

We would like to thank all patients for their time in participating in the focus groups. This research received financial support from the National Health Security Office (NHSO), region 2, Phitsanulok.

\section{Disclosure}

The authors report no conflicts of interest in this work.

\section{References}

1. De Vera MA, Bhole V, Burns LC, Lacaille D. Impact of statin adherence on cardiovascular disease and mortality outcomes: a systematic review. Br J Clin Pharmacol. 2014;78:684-698.

2. Ho SC, Chong HY, Chaiyakunapruk N, Tangiisuran B, Jacob SA. Clinical and economic impact of non-adherence to antidepressants in major depressive disorder: a systematic review. J Affect Disord. 2016; 193:1-10.

3. Ratanawongsa N, Karter AJ, Parker MM, et al. Communication and medication refill adherence: the Diabetes Study of Northern California. JAMA Intern Med. 2013;173:210-218.

4. Lagarde M, Palmer N. The impact of user fees on access to health services in low- and middle-income countries. Cochrane Database Syst Rev. 2011:CD009094.

5. Ryan R, Santesso N, Lowe D, et al. Interventions to improve safe and effective medicines use by consumers: an overview of systematic reviews. Cochrane Database Syst Rev. 2014:CD007768.

6. Blenkinsopp A, Bond C, Raynor DK. Medication reviews. Br J Clin Pharmacol. 2012;74:573-580.

7. Hatah E, Braund R, Tordoff J, Duffull SB. A systematic review and meta-analysis of pharmacist-led fee-for-services medication review. Br J Clin Pharmacol. 2014;77:102-115.

8. Bulajeva A, Labberton L, Leikola S, et al. Medication review practices in European countries. Res Social Adm Pharm. 2014;10:731-740.

9. Anderson C, Blenkinsopp A, Armstrong M. Feedback from community pharmacy users on the contribution of community pharmacy to improving the public's health: a systematic review of the peer reviewed and non-peer reviewed literature 1990-2002. Health Expect. 2004;7:191-202.

10. Gidman W, Ward P, McGregor L. Understanding public trust in services provided by community pharmacists relative to those provided by general practitioners: a qualitative study. BMJ Open. 2012;2: e000939.

11. Saramunee K, Krska J, Mackridge A, Richards J, Suttajit S, PhillipsHoward P. General public's views on pharmacy public health services: current situation and opportunities in the future. Public Health 2015;129:705-715.

12. Saramunee K, Krska J, Mackridge A, Richards J, Suttajit S, PhillipsHoward P. How to enhance public health service utilization in community pharmacy? General public and health providers' perspectives Res Social Adm Pharm. 2014;10:272-284.

13. Rayes IK, Hassali MA, Abduelkarem AR. A qualitative study exploring public perceptions on the role of community pharmacists in Dubai. Pharm Pract (Granada). 2014;12:363.

14. Creswell JW. Qualitative Inquiry and Research Design: Choosing among Five Approaches. Thousand Oaks (CA): Sage Publications; 2012.

15. Huston SA, Hobson EH. Using focus groups to inform pharmacy research. Res Social Adm Pharm. 2008;4:186-205.

16. Kitzinger J. Qualitative research. Introducing focus groups. BMJ. 1995; 311:299-302.
17. Chaiyakunapruk N, Jones SM, Dhippayom T, Sumpradit N. Pharmacy practice in Thailand. In: Fathelrahman AI, Ibrahim MI, Wertheimer AI, editors. Pharmacy Practice in Developing Countries: Achievements and Challenges. Amsterdam: Elsevier; 2016:3-22.

18. Wannasirikul P, Termsirikulchai L, Sujirarat D, Benjakul S, Tanasugarn C. Health literacy, medication adherence, and blood pressure level among hypertensive older adults treated at primary health care centers. Southeast Asian J Trop Med Public Health. 2016;47:109-120.

19. Somprattana C, Poobal P, Wonsawangpanich W, Werawattanachai C, Somrak K, Sriboonruan T. [Perceptions and understandings of drug use in schizophrenia patients at Prasrimahabhodi Psychiatric Hospital] Isan J Pharm Sci. 2014;9 Suppl:72-76. Thai.

20. Zhang NJ, Terry A, McHorney CA. Impact of health literacy on medication adherence: a systematic review and meta-analysis. Ann Pharmacother. 2014;48:741-751.

21. Miller TA. Health literacy and adherence to medical treatment in chronic and acute illness: a meta-analysis. Patient Educ Couns. 2016; 99:1079-1086.

22. Lamberts EJ, Bouvy ML, van Hulten RP. The role of the community pharmacist in fulfilling information needs of patients starting oral antidiabetics. Res Social Adm Pharm. 2010;6:354-364.

23. Dhippayom T, Krass I. Supporting self-management of type 2 diabetes: is there a role for the community pharmacist? Patient Prefer Adherence. 2015;9:1085-1092.

24. Anderson C, Thornley T. "It's easier in pharmacy": why some patients prefer to pay for flu jabs rather than use the National Health Service. BMC Health Serv Res. 2014;14:35.

25. McMillan SS, Sav A, Kelly F, King MA, Whitty JA, Wheeler AJ. How to attract them and keep them: the pharmacy attributes that matter to Australian residents with chronic conditions. Int J Pharm Pract. 2014;22:238-245.

26. Krueger JL, Hermansen-Kobulnicky CJ. Patient perspective of medication information desired and barriers to asking pharmacists questions. J Am Pharm Assoc (2003). 2011;51:510-519.

27. Twigg MJ, Poland F, Bhattacharya D, Desborough JA, Wright DJ. The current and future roles of community pharmacists: views and experiences of patients with type 2 diabetes. Res Social Adm Pharm. 2013;9: 777-789.

28. Shah BK, Patwardhan P, Gadkari A, Chewning B. Patient desire for information from pharmacists and barriers to question-asking. $\mathrm{J} \mathrm{Am}$ Pharm Assoc (2003). 2006;46:270.

29. Latif A, Boardman HF, Pollock K. Understanding the patient perspective of the English community pharmacy medicines use review (MUR). Res Social Adm Pharm. 2013;9:949-957.

30. Bissell P, Blenkinsopp A, Short D, Mason L. Patients' experiences of a community pharmacy-led medicines management service. Health Soc Care Community. 2008;16:363-369.

31. Eades CE, Ferguson JS, O'Carroll RE. Public health in community pharmacy: a systematic review of pharmacist and consumer views. BMC Public Health. 2011;11:582.

32. Insuk $\mathrm{S}$, U-Pakdee $\mathrm{N}$, Thananithisak $\mathrm{C}$, et al. Cost comparison and patients satisfaction on health promotional media on enhanced pharmacy services provided in community pharmacies in Thailand. Poster presented at: US-Thai Consortium; June 1-3, 2016; Khon Kaen, Thailand.

33. Bradley F, Wagner AC, Elvey R, Noyce PR, Ashcroft DM. Determinants of the uptake of medicines use reviews (MURs) by community pharmacies in England: a multi-method study. Health Policy. 2008;88:258-268.

34. Latif A, Boardman H. Community pharmacists' attitudes towards medicines use reviews and factors affecting the numbers performed. Pharm World Sci. 2008;30:536-543.

35. Lee E, Braund R, Tordoff J. Examining the first year of medicines use review services provided by pharmacists in New Zealand: 2008. NZ Med J. 2009;122:3566. 


\section{Supplementary materials Focus-group topic guide and questions}

Issue I: Experiences and opinions on the use of pharmacy services

How do you use the community pharmacy?

Prompts

- How often do you use the community pharmacy?

- Why do you visit the pharmacy?

\section{Issue 2: Drug-related problems}

Do you have problems related to medicines that you currently use?

\section{Prompt}

- If so, how did you deal with it?

\section{Issue 3: Understanding of the use of medicines}

What do you think about your understanding of the use of your medicines?

\section{Prompt}

- Where did you get information about your medicines?

Issue 4: Need and perceived benefit of medicine-use review (MUR) service

What will you do if the pharmacist offers the MUR service to you? Why do you think that?

\section{Prompts}

- What do you think about the benefit of the MUR service?

- What is the appropriate length of time to undertake the service?

\section{Issue 5: Barriers to and facilitators for using MUR}

What factors do you feel encourage you to use the MUR service, and what factors do you feel discourage you from using this service?

\section{Prompts}

- What do you think about locations of pharmacies?

- What do you think about the skills and trainings of pharmacists?

- What do you think about the privacy and confidentiality of the pharmacy premises?

- What do you think about accessibility of pharmacies/ pharmacists?

Issue 6: How to promote uptake of the MUR service What do you think should have been done to make people aware of the MUR service more?

\section{Prompts}

- What would be an effective advertisement to promote the MUR service to targeted patients?

- What do you think should have been done to make people use the MUR service in community pharmacies more?

\section{Issue 7: Contribution of community pharmacies to} improve safe and appropriate use of medicines How could community pharmacies help to improve the safe and appropriate use of medicines?

\section{Prompt}

- Are there any health services that you think should be delivered through pharmacies?
Patient Preference and Adherence

\section{Publish your work in this journal}

Patient Preference and Adherence is an international, peer-reviewed, open access journal that focuses on the growing importance of patient preference and adherence throughout the therapeutic continuum. Patient satisfaction, acceptability, quality of life, compliance, persistence and their role in developing new therapeutic modalities and compounds to optimize

\section{Dovepress}

clinical outcomes for existing disease states are major areas of interest for the journal. This journal has been accepted for indexing on PubMed Central. The manuscript management system is completely online and includes a very quick and fair peer-review system, which is all easy to use. Visit http://www dovepress.com/testimonials.php to read real quotes from published authors. 